\title{
PENERAPAN KODE ETIK JURNALISTIK PADA PENULISAN BERITA AHOK TERKAIT PEMILUKADA DKI JAKARTA 2017 DALAM SURAT KABAR KOMPAS \\ MRR Tiyas Maheni ${ }^{1)}$, Sari Puspita Dewi ${ }^{2)}$ dan Ade Haryani \\ Jurusan Teknik Grafika dan Penerbitan Politeknik Negeri Jakarta \\ Email: ${ }^{1}$ tyasmaheni@gmail.com, ${ }^{2}$ sari.puspitadewi@grafika.pnj.ac.id
}

\begin{abstract}
This research is aimed at describing the application of Journalistic Code of Ethics on news writing related to Ahok in Governor Election of 2017 published by Kompas. The method used is content analysis as in qualitative approach, then the data analysis technique used is a filling system by making the categories based on the Articles 3, 4 and 8 of Journalistic Code of Ethics to classify the obtained data. Results of the study showed that during July to August 2016 Kompas published 4 (four) news articles and applied almost all of the Articles which are the Article 3 paragraph (b), (c), (d), Article 4 paragraph (a), (b), (c), (d), (e), and Article 8 paragraph (a), (b) on its news articles. Only 1 (one) news article which did not apply the Article 3 paragraph (a) about clarifying information.
\end{abstract}

Key words: Journalistic code of ethics, news articles, governor election

\section{PENDAHULUAN}

Dalam sebuah survey terhadap 31 Kode Etik Jurnalistik Eropa, Phelan dalam Larasati (2014) menunjukkan sehubungan dengan prinsip-prinsip profesional, seberapa sering hal-hal tertentu muncul : 40\% dari kode etik merumuskan tanggung jawab wartawan terhadap publik (misalnya kebenaran dan kejelasan informasi, pertahanan hak-hak masyarakat, tanggung jawab, sebagai tokoh dalam posisi pengaruh, opini public), $23 \%$ memuat prinsip-prinsip mengacu pada perlindungan professional integritas jurnalis (perlindungan dari otoritas public, perlindungan dari pengusaha dan dari klien), $22 \%$ tanggung jawab yang berkaitan dengan sumber-sumber informasi yang ditemukan (misalnya persyaratan tentang pengumpulan dan penyajian informasi dan integritas sumber), 9\% dari kode etik tentang perlindungan status dan solidaritas professional, $4 \%$ berisi persyaratan tentang tanggungjawab terhadap pengusaha dan $2 \%$ memiliki persyaratan pada tanggungjawab terhadap lembaga-lembaga negara. Dengan berpedoman pada kode etik jurnalistik, maka aktivitas jurnalistik di Indonesia yaitu praktek jurnalisme yang sehat, bebas dan bertanggungjawab dapat terwujud (Anom, 2008).

Basuki Tjahaya Purnama (Ahok) adalah fenomena tersendiri yang mewarnai perjalanan demokrasi Indonesia, karena untuk pertama kalinya Gubernur Ibu Kota DKI Jakarta berasal dari etnis Tionghoa. Di mana selama era Presiden Soeharto, komunitas minoritas etnis Tionghoa menghadapi diskriminasi terutama bidang politik dan militer. Karir politik Ahok menandai pergeseran peran etnis Tionghoa di Indonesia. Ahok dinilai mencerminkan perubahan tersebut, meski hujan kritik selalu mengiringi gerak langkah dan pernyataan pernyataannya. Ahok pernah menghadapi kampanye hitam ketika mencalonkan diri sebagai wakil gubernur DKI tahun 2002. Di tengah gempuran isu SARA, Basuki Tjahaya Purnama (Ahok) menyatakan pencalonan dirinya melalui jalur Independen, walau pada akhirnya bergabung dengan salah satu partai politik. Meski pemilihan kepala daerah untuk memperebutkan kursi nomer satu di Ibukota Indonesia akan dilaksanakan tahun 2017, namun gegap gempitanya sudah terasa dari sekarang. Media Massa baik cetak maupun elektronik tidak pernah 
luput untuk memberitakannya bahkan beberapa kali menjadi tranding topic dan headline dalam pemberitaan surat kabar.

Demikian halnya dengan surat kabar Kompas, dalam beberapa headline-nya sering menampilkan berita tentang Ahok. Sebuah situs pemeringkat surat kabar dunia, '4 International Media \& news Paper www.4imn.com' menyatakan bahwa Kompas adalah harian surat kabar yang masuk dalam daftar 3 (tiga) besar surat kabar terpopuler di Indonesia, selain itu Kompas adalah surat kabar nasional yang tertinggi oplah dan sebarannya (http://nasional,republika.co.id). Dengan demikian, Kompas adalah surat kabar yang dapat memiliki pengaruh besar dalam pembentukan opini publik, sehingga sangat dituntut untuk menerapkan kode etik jurnalistik dalam penulisan berita yang dimuat.

Berdasarkan uraian tersebut di atas, perlu untuk diketahui bagaimana Kompas menerapkan Kode Etik Jurnalistik dalam penulisan berita yang dimuat tidak terkecuali dalam penulisan berita tentang Ahok.

\section{Rumusan Masalah}

Sebuah berita diharapkan: 1) telah teruji informasinya, berimbang, tidak mencampurkan fakta dan opini yang menghakimi, serta menerapkan asas praduga tak bersalah. 2) bukan berita bohong, fitnah, sadis, dan cabul, dan 3) tidak ditulis berdasarkan prasangka atau diskriminasi terhadap seseorang atas dasar perbedaan suku, ras, warna kulit, agama yang tertuang dalam Kode Etik Jurnalistik yang ditetapkan oleh Dewan Pers melalui Surat Keputusan No.03/SK-DP/III/2006.

Oleh karena itu, pokok masalah yang akan diungkap dalam penelitian ini adalah:

1. Apakah Kompas menerapkan Kode Etik Jurnalistik dalam penulisan berita khususnya pada pemberitaan Ahok?

2. Ketentuan Pasal apa saja yang sering diterapkan oleh Kompas dalam penulisan berita Ahok?
Adapun batasan ruang lingkup penelitian ini dijabarkan sebagai berikut :

1. Kode Etik Jurnalistik adalah penerapan Pasal 3, 4, dan 8 Kode etik Jurnalistik yang ditetapkan oleh Dewan Pers melalui Surat Keputusan No.03/SKDP/III/2006.

2. Berita adalah berita yg memuat pemberitaan tentang Ahok terkait pencalonan dirinya sebagai gubernur DKI Jakarta dalam pemilukada 2017.

3. Surat kabar adalah harian surat kabar Kompas selama bulan Juli dan Agustus 2016

\section{METODE PENELITIAN}

Penelitian ini merupakan penelitian deskriptif kualitatif, dengan metode analisis isi dengan pendekatan kualitatif. Metode ini digunakan untuk mendeskripsikan penerapan Kode Etik Jurnalistik pada konten berita yang diterbitkan oleh Kompas dalam pemberitaan Ahok terkait pencalonan dirinya dalam Pemilukada DKI Jakarta 2017. Menurut Berg dan Lune dalam Lesmana (2016:5) analisis isi adalah penjelasan dan interpretasi data yang detail dan sistematis dalam upaya untuk mengidentifikasi pola, tema, bias dan arti dari sebuah pesan. Metode analisis ini dipergunakan dalam banyak disiplin ilmu, termasuk sosiologi, kriminologi, psikologi, pendidikan, bisnis, jurnalisme, seni dan politik.

Analisis isi kualitatif ini menggunakan pendekatan summative content analysis yang dimulai dari keberadaan kata atau frase dalam sebuah teks, kemudian akan dilakukan eksplorasi dengan melihat arti laten dan tema yang tampak pada data, yakni pada tulisan, gambar, foto maupun grafis dalam pemberitaan Ahok. Hasil analisis terhadap teks berita akan menunjukkan apakah Pasal 3, 4, dan 8 Kode Etik Jurnalistik diterapkan oleh Kompas dan Republika dalam penulisan berita Ahok. 
Pengumpulan data dalam penelitian ini menggunakan metode proses dokumentasi dari surat kabar Kompas edisi Juli dan Agustus 2016 dilanjutkan dengan menggunakan codding sheet atau lembar koding untuk memasukkan data-data yang telah dikumpulkan berdasarkan kategori yang telah ditetapkan sebelumnya. Setelah data terkumpul dalam bentuk koding, selanjutnya dilakukan proses pengelompokan dan analisis.

\section{HASIL DAN PEMBAHASAN}

Ketentuan dalam Pasal 3, 4, dan 8 Kode Etik Jurnalistik, dikelompokkan menjadi beberapa poin yang akan diteliti yaitu:

1. Selalu menguji informasi,
2. Memberitakan secara berimbang,

3. Tidak memuat opini yang menghakimi,

4. Menerapkan asas praduga tak bersalah,

5. Tidak membuat berita bohong,

6. Tidak membuat berita fitnah,

7. Tidak membuat berita sadis,

8. Tidak membuat berita cabul,

9. Mencantumkan waktu pengambilan gambar dan suara

10. Tidak menulis berita berdasarkan prasangka dan,

11. Tidak membuat berita berdasarkan diskriminasi.

Di bawah ini berita tentang Ahok dalam surat kabar Kompas di bulan Juli dan Agustus 2016 yang dikelompokkan berdasarkan tema berita dengan rincian sebagai berikut:

Tabel 1. Pengelompokan Berita

\begin{tabular}{|c|c|c|c|c|}
\hline & NAMA SURAT & & & \\
\hline NO. & KABAR & TANGGAL & TEMA & JUDUL \\
\hline 1 & Kompas & Kamis, 28 Juli 2016 & Pemilukada & $\begin{array}{l}\text { Partai Politik dan Teman Ahok } \\
\text { Bersatu }\end{array}$ \\
\hline 2 & Kompas & Sabtu, 30 Juli 2016 & Pemilukada & $\begin{array}{l}\text { Gerindra Ajukan Uno, PDI-P Buka } \\
\text { Peluang Basuki }\end{array}$ \\
\hline 3 & Kompas & Sabtu, 13 Agustus 2016 & Pemilukada & $\begin{array}{l}\text { Calon Berkomitmen Bersaing } \\
\text { Sehat }\end{array}$ \\
\hline 4 & Kompas & Jumat, 26 Agustus 2016 & Pemilukada & $\begin{array}{l}\text { Dukungan Resmi bagi Kedua } \\
\text { Calon } \\
\text { Gubernur DKI Jadi Saksi Kasus }\end{array}$ \\
\hline 5 & Kompas & Jumat, 15 Juli 2016 & Lain-lain & Tanah Cengkareng \\
\hline 6 & Kompas & Selasa, 26 Juli 2016 & Lain-lain & $\begin{array}{l}\text { Basuki Pertahankan Kontribusi } \\
\text { Gubernur-DPRD Sepakat Menata }\end{array}$ \\
\hline 7 & Kompas & Selasa, 30 Agustus 2016 & Lain-lain & Ulang Kemang \\
\hline
\end{tabular}

Sumber: Data Primer yang diolah

Berdasarkan tabel di atas, bahwa selama bulan Juli - Agustus 2016 Kompas memuat 7 (tujuh) berita. Dari keseluruhan berita tersebut, terdapat 4 berita Ahok yang terkait dengan pencalonan dirinya sebagai Gubernur DKI Jakarta dalam pemilukada 2017. Keseluruhan berita
Ahok terkait dengan pilkada tersebut akan dianalisis untuk melihat apakah Kompas menerapkan kode etik jurnalistik. 
Tabel 2. Penerapan Kode Etik Jurnalistik Pada Surat Kabar Kompas

\begin{tabular}{|c|c|c|c|c|c|c|c|c|c|c|c|c|c|c|c|c|c|c|c|c|c|c|c|}
\hline \multirow{3}{*}{ No } & \multirow{3}{*}{ Judul Berita } & \multicolumn{22}{|c|}{ Kategori } \\
\hline & & \multicolumn{2}{|c|}{$\begin{array}{l}\text { (1) } \\
\text { Selalu } \\
\text { menguji } \\
\text { informasi }\end{array}$} & \multicolumn{2}{|c|}{$\begin{array}{l}\text { (2) } \\
\text { Berimban } \\
\mathrm{g}\end{array}$} & \multicolumn{2}{|c|}{$\begin{array}{l}\text { (3) } \\
\text { Tdk } \\
\text { mencamp } \\
\text { urkan } \\
\text { Fakta dan } \\
\text { opini yg } \\
\text { menghaki } \\
\text { mi }\end{array}$} & \multicolumn{2}{|c|}{$\begin{array}{l}(4) \\
\text { Asas } \\
\text { praduga } \\
\text { tak } \\
\text { bersalah }\end{array}$} & \multicolumn{2}{|c|}{$\begin{array}{l}\text { (5) } \\
\text { Tdk } \\
\text { memuat } \\
\text { berita } \\
\text { bohong }\end{array}$} & \multicolumn{2}{|c|}{$\begin{array}{l}(6) \\
\text { Tdk } \\
\text { memuat } \\
\text { berita } \\
\text { fitnah }\end{array}$} & \multicolumn{2}{|c|}{$\begin{array}{l}\text { (7) } \\
\text { Tdk } \\
\text { memuat } \\
\text { berita } \\
\text { sadis }\end{array}$} & \multicolumn{2}{|c|}{$\begin{array}{l}\text { (8) } \\
\text { Tdk } \\
\text { memuat } \\
\text { berita } \\
\text { cabul }\end{array}$} & \multicolumn{2}{|c|}{$\begin{array}{l}\text { (9) } \\
\text { mencantu } \\
\text { mkan } \\
\text { waktu } \\
\text { pengambil } \\
\text { an } \\
\text { gambar } \\
\text { dan suara }\end{array}$} & \multicolumn{2}{|c|}{$\begin{array}{l}(10) \\
\text { Tdk } \\
\text { berdasark } \\
\text { an } \\
\text { prasangka }\end{array}$} & \multicolumn{2}{|c|}{$\begin{array}{l}\text { (11) } \\
\text { Tdk } \\
\text { mengandu } \\
\text { ng } \\
\text { diskrimin } \\
\text { asi }\end{array}$} \\
\hline & & ya & tdk & ya & tdk & ya & tdk & ya & tdk & ya & tdk & ya & tdk & ya & tdk & ya & tdk & уа & tdk & ya & tdk & уа & tdk \\
\hline 1 & $\begin{array}{l}\text { Partai Politik } \\
\text { dan Teman } \\
\text { Ahok Bersatu }\end{array}$ & $\sqrt{ }$ & - & $\sqrt{ }$ & - & $\sqrt{ }$ & - & $\sqrt{ }$ & - & $\sqrt{ }$ & - & $\sqrt{ }$ & - & $\sqrt{ }$ & - & $\sqrt{ }$ & - & $\sqrt{ }$ & - & $\sqrt{ }$ & - & $\sqrt{ }$ & - \\
\hline 2 & $\begin{array}{lr}\text { Gerindra } & \\
\text { Ajukan } & \text { Uno, } \\
\text { PDI-P } & \text { Buka } \\
\text { Peluang Basuki }\end{array}$ & $\sqrt{ }$ & - & $\sqrt{ }$ & - & $\sqrt{ }$ & - & $\sqrt{ }$ & - & $\sqrt{ }$ & - & $\sqrt{ }$ & - & $\sqrt{ }$ & - & $\sqrt{ }$ & - & $\sqrt{ }$ & - & $\sqrt{ }$ & - & $\sqrt{ }$ & - \\
\hline 3 & $\begin{array}{l}\text { Calon } \\
\text { Berkomitmen } \\
\text { Bersaing Sehat }\end{array}$ & $\sqrt{ }$ & - & $\sqrt{ }$ & - & $\sqrt{ }$ & - & $\sqrt{ }$ & - & $\sqrt{ }$ & - & $\sqrt{ }$ & - & $\sqrt{ }$ & - & $\sqrt{ }$ & - & $\sqrt{ }$ & - & $\sqrt{ }$ & - & $\sqrt{ }$ & - \\
\hline 4 & $\begin{array}{l}\text { Dukungan } \\
\text { Resmi bagi } \\
\text { Kedua Calon }\end{array}$ & - & $\sqrt{ }$ & $\sqrt{ }$ & - & $\sqrt{ }$ & - & $\sqrt{ }$ & - & $\sqrt{ }$ & - & $\sqrt{ }$ & - & $\sqrt{ }$ & - & $\sqrt{ }$ & - & $\sqrt{ }$ & - & $\sqrt{ }$ & - & $\sqrt{ }$ & - \\
\hline
\end{tabular}

Sumber : Data Primer yang diolah.

Berdasarkan tabel di atas, bahwa selama bulan Juli dan Agustus 2016, surat Kabar Kompas hanya memuat 4 (empat) berita Ahok yang terkait dengan Pemilukada DKI 2017. Dari keseluruhan berita tersebut 3 (tiga) berita telah memenuhi atau menerapkan seluruh ketentuan Pasal 3, 4 dan 8 Kode etik Jurnalistik dan 1 (satu) penulisan berita yang belum menerapkan secara keseluruhan.

Tiga (3) berita yang telah menerapkan secara keseluruhan ketentuan Pasal 3, 4 dan 8 kode etik Jurnalistik adalah berita "Partai Politik dan Teman Ahok Bersatu", "Gerindra Ajukan Uno, PDI-P Buka Peluang Basuki", dan "Calon Berkomitmen Bersaing Sehat”. Penulisan ketiga berita yang dimuat dalam surat kabar Kompas tersebut telah menguji informasi, berimbang, tidak mencampurkan fakta dan opini yang menghakimi, memuat asas praduga tak bersalah, tidak memuat berita bohong, fitnah, sadis dan cabul, mencantumkan waktu pengambilan gambar dan suara, tidak berdasarkan prasangka dan tidak mengandung dikriminasi

Sedangkan pada penulisan 1 (satu) berita yang lain, yaitu dalam berita "Dukungan Resmi bagi Kedua Calon"
Surat Kabar Kompas tidak menerapkan ketentuan Pasal 3 poin (a) yaitu tentang menguji informasi. Sedangkan pada ketentuan Pasal 3 yang lain, yaitu pada poin (b), (c) dan (d) , dan juga ketentuan Pasal 4 dan 8 telah diterapkan.

Dengan demikian, maka Surat Kabar Kompas dalam seluruh penulisan berita Ahok terkait pemilukada ini, telah menerapkan seluruh ketentuan Pasal 4, baik poin (a, b, c, d dan e) dan juga ketentuan Pasal 8 poin (a) dan (b). Sedangkan untuk penerapan Pasal 3 terjadi satu pelanggaran yaitu pada poin (a), meskipun begitu pada ketentuan Pasal 3 yang lain yaitu pada poin (b), (c) dan (d) selalu diterapkan.

\section{KESIMPULAN DAN SARAN Kesimpulan}

Berdasarkan analisa yang telah dilakukan pada bab sebelumnya, maka dapat diambil kesimpulan sebagai berikut :

1. Bahwa selama bulan Juli dan Agustus 2016 terkait Pemilukada DKI Jakarta 2017, Surat Kabar Kompas hanya memuat 4 (empat) berita. Meskipun begitu mayoritas ketentuan Pasal 3, 4 dan 8 Kode Etik Jurnalistik telah diterapkan, yaitu: 1) menguji informasi, memberitakan secara berimbang, tidak 
mencampurkan fakta dan opini yang menghakimi, serta menerapkan asas praduga tak bersalah. 2) Tidak membuat berita bohong, fitnah, sadis, dan cabul serta mencantumkan waktu pengambilan gambar dan suara (jika memuatnya), dan 3) tidak menulis atau menyiarkan berita berdasarkan prasangka atau diskriminasi.

2. Meskipun begitu terdapat satu penulisan berita yang tidak menerapkan ketentuan Pasal 3 poin (a) tentang menguji informasi, sedangkan dalam penulisan berita yang lain telah diterapkan. Dengan demikian dalam penelitian ini, pasal yang selalu diterapkan oleh Kompas adalah ketentuan Pasal 3 poin (b), (c), (d), serta seluruh ketentuan Pasal 4 dan 8 Kode Etik Jurnalistik.

\section{Saran}

Berdasarkan hasil penelitian ini, maka untuk penelitian selanjutnya dapat disarankan hal sebagai berikut :

1. Sebagai Surat Kabar yang berskala nasional, meskipun dengan intensitas penerapan Kode Etik Jurnalistik yang berbeda, perlu untuk diketahui alasan atau faktor-faktor yang mempengaruhi tidak diterapkannya beberapa ketentuan Kode Etik Jurnalistik dalam penulisan sebuah berita.

2. Lebih lanjut perlu untuk diketahui tindakan yang dilakukan Dewan Pers terhadap media massa (cetak) yang tidak menerapkan Kode Etik Jurnalistik dalam penulisan berita.

\section{DAFTAR PUSTAKA}

Barus, Sedia Willing. 2010. Jurnalistik, Petunjuk Teknis Menulis Berita. Jakarta: Penerbit Erlangga Ishwara.
Luwi, 2011. Jurnalisme Dasar. Jakarta: Penerbit Buku Kompas.

Kusumaningrat, Hikmat Purnama. 2009. Jurnalistik Teori dan Praktik Edisi ke

4. Bandung: Penerbit Erlangga.

Kovach dan Rosensteil, Tom. 2001. The Element of Journalism. New York: Crown Publishers.

Sumadirian, Haris. 2010. Jurnalistik Indonesia: Menulis Berita dan Feature Edisi ke 2. Bandung: Penerbit Simbiosa Rekatama Media.

Wiryawan, Hari. 2007. Dasar-dasar Hukum Media. Yogyakarta: Pustaka Pelajar.

\section{Jurnal:}

Anom, E. 2008. Jurnalisme Bebas dan Bertanggung Jawab. Jurnal Ilmu Komunikasi Esa Unggul, Vol.1 No.1. diakses 4 April 2016.

Daulay, Hamdan. 2008. Kode Etik Jurnalistik dan Kebebasan Pers di Indonesia ditinjau dari Perspektif Islam. Jurnal Penelitian Agama, Vol.XVII No.2 MB-Agustus. Diakses 4 April 2016.

Larasati, Niken. 2014. Penerapan Kode Etik Jurnalistik pada Rubrik Berita Nganal Kodew dalam Surat Kabar Radar Malang. Jurnal Universitas Brawijaya Malang. Diakses 4 April 2016.

\section{Peraturan:}

SK Dewan Pers No. 03/SK-DP/III/2006 tangal 24 Maret 2016 Tentang Kode Etik Jurnalistik.

UU No. 40 Tahun 1999 Tentang Pers.

SK Dewan Pers No.1/SK-DP/2000 tanggal 20 Juni 2000 Tentang Kode Etik Wartawan Indonesia 